\title{
Malignant peripheral nerve sheath tumour arising within neurofibroma. An immunohistochemical analysis in the comparison between benign and malignant components
}

\author{
T Watanabe, Y Oda, S Tamiya, K Masuda, M Tsuneyoshi
}

\begin{abstract}
Aims-To compare the expression of immunohistochemical variables between benign and malignant components of malignant peripheral nerve sheath tumour (MPNST) arising within neurofibroma.

Methods-Eight cases of MPNST arising within a neurofibroma, associated with neurofibromatosis type 1 (NF1), were studied. The areas of MPNST and neurofibroma were compared immunohistochemically with regard to the expression of proliferative activity (MIB-1), growth factors, p53, bcl-2, neural cell adhesion molecule (N-CAM), and CD34.

Results-The expression of transforming growth factor $\beta 1$ (TGF- $\beta 1)$, TGF- $\beta$ receptor type II, hepatocyte growth factor $\alpha$ (HGF- $\alpha$ ), c-met, p53, and N-CAM was higher in the areas of MPNST than in the neurofibromatous areas in four, five, five, eight, five, and three of the eight cases, respectively. CD34 expression was lower in the areas of MPNST than in the neurofibroma areas in three of the eight cases.

Conclusions-On the basis of these findings, TGF- $\beta 1, \mathrm{HGF}-\alpha$, and p53 might be involved in the malignant transformation of neurofibroma to MPNST.

(F Clin Pathol 2001;54:631-636)
\end{abstract}

Keywords: malignant peripheral nerve sheath tumour; neurofibroma; immunohistochemistry; transforming growth factor $\beta$; hepatocyte growth factor; $\mathrm{p} 53$

Malignant peripheral nerve sheath tumour (MPNST) is a malignant neurogenic tumour that occurs with high frequency in association with neurofibromatosis type 1 , arising either de novo or in transition from neurofibroma. ${ }^{1}$ There have been many studies of MPNST and neurofibroma ${ }^{2-17}$; however, only a few have

Accer publication

20 November 2000

Table 1 Clinical summary

\begin{tabular}{lllllll}
\hline $\begin{array}{l}\text { Age } \\
\text { Case } \\
\text { (years) }\end{array}$ & Sex & Site & Size $(\mathrm{cm})$ & Treatment & Follow up \\
\hline 1 & 60 & $\mathrm{M}$ & Forearm & 1.6 & Surgery & Alive (147 mo) \\
2 & 37 & $\mathrm{M}$ & Lower leg & 4 & Surgery & Dead (32 mo) \\
3 & 52 & $\mathrm{~F}$ & Chest & 4.3 & Surgery & Alive (58 mo) \\
4 & 62 & $\mathrm{~F}$ & Abdomen & 11 & Surgery & Alive (65 mo) \\
5 & 17 & $\mathrm{M}$ & Retroperitoneum & 15 & Surgery & Dead (16 mo) \\
6 & 27 & $\mathrm{M}$ & Thigh & 27 & Surgery & Dead (11 mo) \\
7 & 32 & $\mathrm{~F}$ & Thigh & 5 & Surgery & Alive (15 mo) \\
8 & 38 & $\mathrm{M}$ & Neck & 6 & Surgery & Dead (7 mo) \\
\hline
\end{tabular}

mo, months. dealt with the immunohistochemical comparison between the sarcomatous area and the adjacent neurofibromatous area in MPNST arising within a neurofibroma. ${ }^{5-7}$

It has been reported that cultured rat Schwann cells respond to some mitogens, including transforming growth factor $\beta$ (TGF$\beta$ ), hepatocyte growth factor (HGF), and platelet derived growth factor (PDGF) ${ }^{18-21}$ In addition, accumulation of some mitogens, such as $\mathrm{HGF}$ and basic fibroblast growth factor (FGF), has also been found in neurofibromatosis. $^{22}{ }^{23}$ TGF- $\beta$ isoforms have been reported to mediate their activity by high affinity binding to the type II receptor. ${ }^{24}$ They inhibit the proliferation of epithelial cells or epithelial tumour cells, but promote the synthesis of extracellular matrix. ${ }^{25}$ However, their role in the tumorigenesis of sarcomas, including neurogenic tumour, has not yet been reported.

$\mathrm{HGF} / \mathrm{c}-\mathrm{met}$ autocrine signalling systems have been suggested to contribute to tumour progression in several carcinomas and sarcomas, including MPNST. ${ }^{26-28}$ However, differences in the expression of $\mathrm{HGF} / \mathrm{c}$-met between areas of neurofibroma and MPNST have not yet been clarified.

Mutations of the p53 gene have also been found in some neurogenic tumours. ${ }^{29-31}$ More recently, neural cell adhesion molecule (NCAM) and CD34, which is a myeloid progenitor cell antigen found in some fibroblast subsets, have been studied in relation to tumour behaviour. ${ }^{32-34}$

In our study, we examined immunohistochemically the expression of these factors, which are considered to be responsible for the development and progression of MPNST, using paraffin wax embedded tissue specimens. In addition, we compared the topological difference in expression of the above factors between the sarcomatous and neurofibromatous areas.

\section{Materials and methods}

SPECIMENS

Eight cases of MPNST arising within a neurofibroma were selected from 69 cases of MPNST registered in the files of the second department of pathology, Kyushu University, Fukuoka, Japan, from 1980 to 1997. We defined MPNST within a neurofibroma as a tumour in which a sarcomatous area was surrounded by a neurofibromatous area. In the sarcomatous area, the tumour was characterised by a proliferation of wavy and buckled 
Table 2 Antibodies used in our study

\begin{tabular}{lllll}
\hline Antibody/antigen & Type & Source & Dilution & Positive control \\
\hline MIB-1 & Mouse & Immunotech & $1 / 100$ & Normal skin \\
p53 (PAb1801) & Mouse & Calbiochem & $1 / 100$ & Adenocarcinoma of the stomach \\
bcl-2 & Mouse & Calbiochem & $1 / 100$ & Normal lymph node \\
TGF $\beta 1$ & Rabbit & Santa Cruz & $1 / 250$ & Normal colon \\
TGF $\beta$ receptor II & Rabbit & Santa Cruz & $1 / 250$ & Normal colon \\
HGF $\alpha$ & Rabbit & IBL & $1 / 50$ & Fibloblasts of the inflamed urinary bladder \\
c-met & Rabbit & Santa Cruz & $1 / 500$ & Normal skin \\
PDGF & Rabbit & Calbiochem & $1 / 250$ & Normal skin \\
PDGF receptor $\beta$ & Mouse & Oncogene Science & $1 / 50$ & Normal skin \\
N-CAM & Mouse & Novo Castra & $1 / 50$ & Neuroblastoma \\
CD34 & Mouse & Novo Castra & $1 / 50$ & Haemangioma \\
\hline
\end{tabular}

HGF, hepatocyte growth factor; N-CAM, neural cell adhesion molecule; PDGF, platelet derived growth factor; TGF, transforming growth factor.

spindle cells. Densely cellular fascicles alternated with hypocellular zones. Mitotic activity was present. The patients, comprising five men and three women, ranged in age from 17 to 62 years (mean, 40.6). All the patients had von Recklinghausen's disease (neurofibromatosis type 1). Table 1 summarises the clinical data of these patients. The histological sections were stained with haematoxylin and eosin, and for each of the tumours the sections with the most characteristic features of both neurofibroma and MPNST were selected for immunohistochemical studies. All of the light microscopic and immunohistochemical studies were performed on formalin fixed, paraffin wax embedded materials.

IMMUNOHISTOCHEMICAL STUDY

Formalin fixed paraffin wax embedded tissue sections ( $4 \mu \mathrm{m}$ thick) were mounted on to glass slides coated with 3-aminopropyltriethoxy silane, before being air dried overnight at room

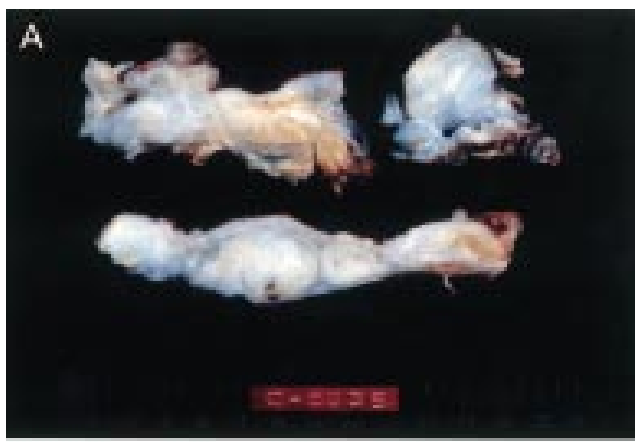

B

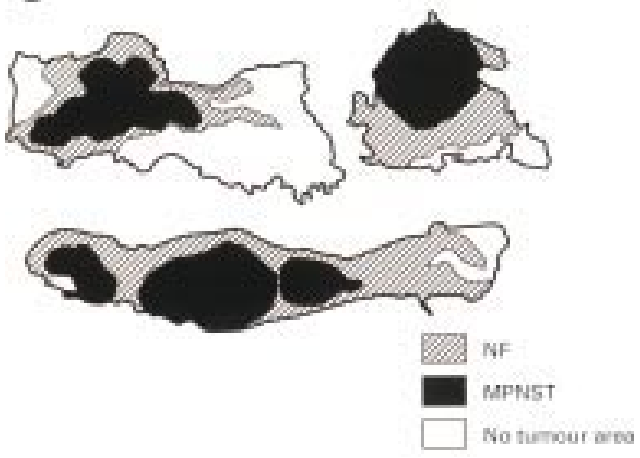

Figure 1 (A) Cut surface of the resected tumour in case 3. Section shows a multinodular solid and white mass. The central firm portion blends with the surrounding subcutaneous fat and muscular tissue. (B) Topographical distribution of histological features of both malignant peripheral nerve sheath tumour and neurofibroma in case 3 . temperature. The sections were dewaxed in xylene and rehydrated in ethanol, and endogenous peroxidase was blocked by methanol containing $0.3 \%$ hydrogen peroxide for 30 minutes. For the purpose of antigen retrieval, the sections were placed in plastic jars containing $0.1 \%$ Tween 20 in citrate buffer and then heated in a microwave oven (H2800 microwave processor; Energy Beam Science, Massachusetts, USA) at $99^{\circ} \mathrm{C}$ for 20 minutes. Nonspecific protein binding was inhibited by treatment with normal rabbit serum (for mouse monoclonal antibodies) or goat serum (for rabbit polyclonal antibodies) for 10 minutes. Sections were incubated at $4^{\circ} \mathrm{C}$ overnight with primary antibodies, before being stained with the streptoavidin-biotin complex/horseradish peroxidase (SAB/HRP) method using a Histofine SAB-PO(M) immunohistochemical staining kit (Nichirei, Tokyo, Japan). The sections were then reacted with a 3,3'diaminobenzidine, peroxytrichloride substrate solution, counterstained with haematoxylin, and mounted. Table 2 summarises the primary antibodies used in our study. The degree of

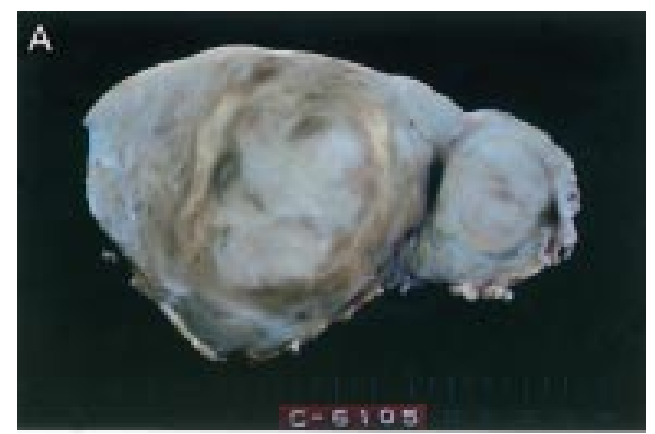

B

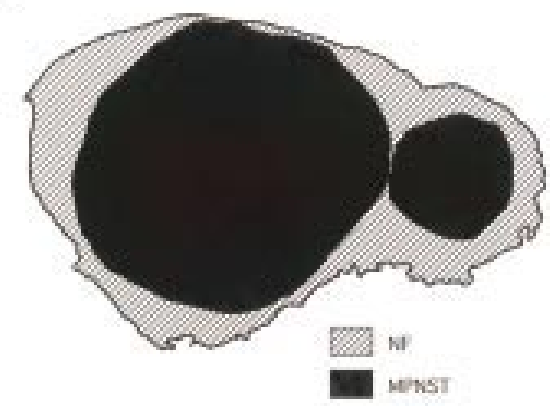

Figure 2. (A) Cut surface of the resected tumour in case 4 The section shows a well circumscribed solid and greyish yellow mass with nodular growth pattern and interlacing fascicles. (B) Topographical distribution of both sarcomatous and neurofibromatous components in case 4. 

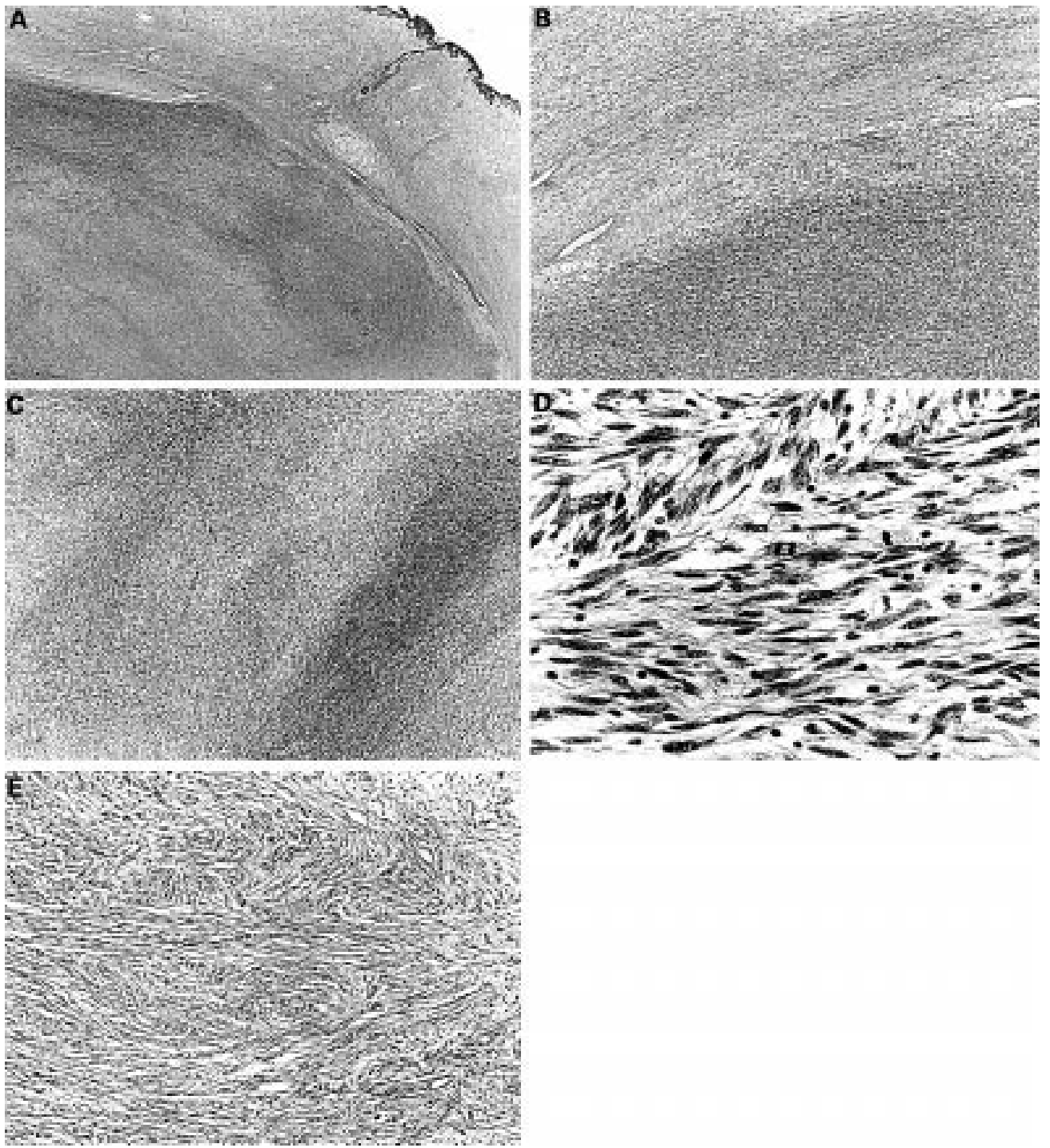

Figure 3 (A-D) Histological picture exhibiting the features of neurofibroma and malignant peripheral nerve sheath tumour (MPNST) (case 4). (A) The MPNST area is surrounded by a neurofibromatous area. Densely cellular fascicles alternate with hypocellular zones in the MPNST area (haematoxylin and eosin stained; original magnification, $\times 12)$. (B) The tumour is composed of interlacing bundles of elongated cells with wavy nuclei, without atypism in the neurofibroma (top), and with atypism in the MPNST (bottom) (haematoxylin and eosin stained; original magnification, $\times 20)$. (C) The tumour is composed of wavy spindle cells arranged in fascicles and with wavy nuclei. Densely cellular fascicles alternate with hypocellular zones (haematoxylin and eosin stained; original magnification, $\times 25$ ). (D) The nuclei of some tumour cells are wavy or buckled. Mitotic figures are seen frequently (haematoxylin and eosin stained; original magnification, $\times 570$ ). (E) Histological picture exhibiting the features of neurofibroma (case 4). The tumour is made up of interlacing bundles of elongated cells with wavy nuclei, without atypism, associated with wire-like strands of collagen (haematoxylin and eosin stained; original magnification, $\times 125$ ).

staining was classified as: negative $(<3 \%$ of the cells), $1+$ (positive; $3-50 \%$ of the cells), and $2+$ (strongly positive; $>50 \%$ of the cells).

The MIB-1 labelling index (LI) was estimated by counting the number of positive cells/1000 tumour cells.

\section{Results}

Figures 1 (case 3) and 2 (case 4) demonstrate the topographic distinctions between the sarcomatous areas and the neurofibromatous areas. In these cases, the sarcomatous components were located within the central region of the entire tumour. Microscopically, in case 4, the sarcomatous area was composed of spindle cells arranged in fascicles adjacent to the neurofibromatous area (fig $3 \mathrm{~A}$ and $\mathrm{B}$ ). Densely cellular fascicles alternated with hypocellular zones (fig 3C). The nuclei of some tumour cells were wavy or buckled (fig 3D). Mitotic figures were seen frequently. The surrounding less cellular area of case 4 showed interlacing bundles of elongated cells, which had wavy nuclei without atypism associated with wire-like strands of collagen (fig 3E). The other tumour (case 5) showed a whorled structure, which was reminiscent of tactoid differentiation (fig 4).

Tables 3-5 summarise the results of our immunohistochemical analyses.

The MIB-1 LI for both the neurofibroma and the MPNST areas ranged from 3.3 to 49.8 , with a mean (SD) of 19.0 (15.7). The MIB-1 LI was found to be higher in the MPNST areas than in the neurofibroma areas (mean, 31.9; SD $11.7 v$ mean, 6.1; SD, 2.4; $\mathrm{p}=0.0001)($ table 3$)$. 


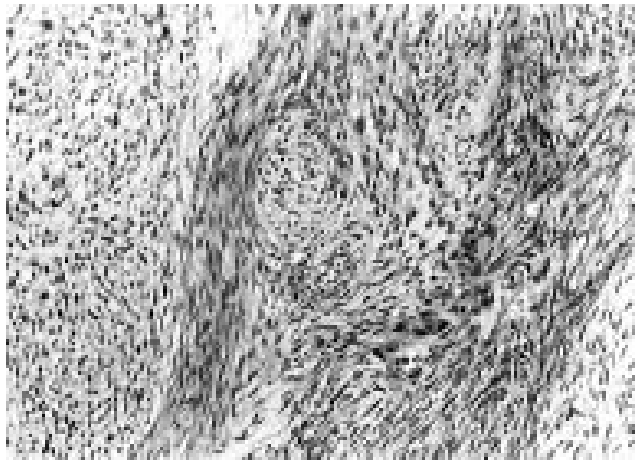

Figure 4 Histological picture exhibiting the features of malignant peripheral nerve sheath tumour (case 5). The tumour is composed of spindle cells arranged in fascicles reminiscent of tactoid differentiation. Nuclei are wavy and twisted (haematoxylin and eosin stained; original magnification, $\times 200$ ).

Table 3 MIB-1 staining

\begin{tabular}{lll}
\hline \multirow{3}{*}{ Case } & \multicolumn{2}{l}{$M I B-1 L I$} \\
\cline { 2 - 3 } & $N F$ & MPNST \\
\hline 1 & 5.5 & 21.3 \\
2 & 6.5 & 37.3 \\
3 & 6.9 & 23.3 \\
4 & 3.5 & 14.5 \\
5 & 4.3 & 41.8 \\
6 & 9.7 & 49.8 \\
7 & 8.7 & 36.7 \\
8 & 3.3 & 30.8 \\
\hline
\end{tabular}

LI, labelling index; MPNST, malignant peripheral nerve sheath tumour; NF, neurofibroma.

Positive reactions with TGF- $\beta 1$, TGF- $\beta$ receptor type II, $\mathrm{HGF}-\alpha$, and c-met were observed more frequently in the MPNST areas than in the neurofibroma areas in four, five, five, and four of the eight cases, respectively (fig 5). A positive reaction with PDGF was found more frequently in the MPNST areas than in the neurofibroma areas in two of the eight

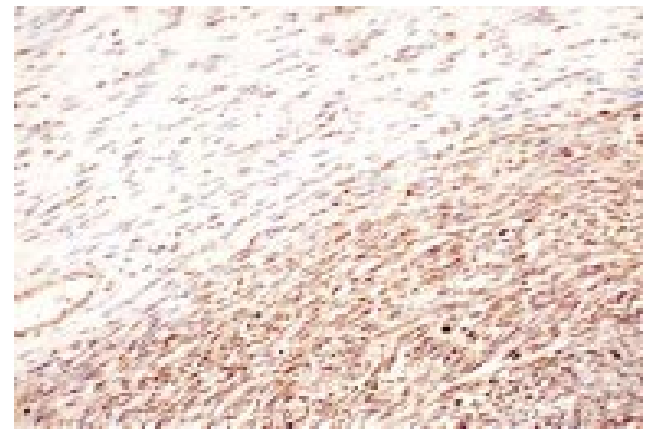

Figure 5 Immunohistochemical staining patterns of the transforming growth factor $\beta$ receptor type II. The degree of staining in the neurofibroma (top) is graded as $1+$, whereas that in the MPNST (bottom) is graded as 2+ (case 5) (original magnification, $\times 200$ ).

cases. However, positive reactions with PDGF receptor $\beta$ were seen in only one case (case 7 ).

Immunoreactivity for bcl-2 was similar in both the MPNST and neurofibroma areas.

In contrast, five of the eight cases showed immunoreactivity for $\mathrm{p} 53$ in the MPNST areas, whereas three of the eight cases showed no immunoreactivity in either the MPNST or neurofibroma areas (fig 6).

Furthermore, N-CAM positivity was seen more frequently in the MPNST areas than in neurofibroma areas in three of the eight cases. In addition, CD34 positive cells were present in the neurofibroma areas, but not in the MPNST areas in three of the eight cases (fig 7).

\section{Discussion}

We speculated that many factors were involved in the malignant transformation from neurofibroma to MPNST. To clarify the mechanisms and factors underlying this transformation, we selected a total of eight cases of MPNST arising within a neurofibroma and undertook immunohistochemical studies.

Table 4 Staining in neurofibroma (NF) and malignant peripheral nerve sheath tumour (MPNST) areas

\begin{tabular}{|c|c|c|c|c|c|c|c|c|c|c|c|c|}
\hline \multirow[b]{2}{*}{ Case } & \multicolumn{2}{|c|}{$T G F-\beta 1$} & \multicolumn{2}{|c|}{$\begin{array}{l}\text { TGF- } \beta \text { receptor } \\
I I\end{array}$} & \multicolumn{2}{|c|}{$H G F-\alpha$} & \multicolumn{2}{|c|}{ c-met } & \multicolumn{2}{|c|}{$P D G F$} & \multicolumn{2}{|c|}{ PDGF receptor $\beta$} \\
\hline & $N F$ & MPNST & $N F$ & MPNST & $N F$ & MPNST & $N F$ & MPNST & $N F$ & $M P N S T$ & $N F$ & MPNST \\
\hline 1 & $1+$ & $2+$ & $1+$ & $2+$ & $1+$ & $2+$ & $1+$ & $2+$ & $1+$ & $2+$ & - & - \\
\hline 2 & $2+$ & $2+$ & $2+$ & $2+$ & $1+$ & $2+$ & $1+$ & $2+$ & $1+$ & $2+$ & - & - \\
\hline 3 & $2+$ & $2+$ & $2+$ & $2+$ & $2+$ & $2+$ & $2+$ & $2+$ & $1+$ & $1+$ & - & - \\
\hline 4 & $1+$ & $2+$ & $1+$ & $2+$ & $1+$ & $2+$ & $1+$ & $2+$ & $1+$ & $1+$ & - & - \\
\hline 5 & $1+$ & $2+$ & $1+$ & $2+$ & $2+$ & $2+$ & $2+$ & $2+$ & $1+$ & $1+$ & - & - \\
\hline 6 & $2+$ & $2+$ & $1+$ & $2+$ & $1+$ & $2+$ & $2+$ & $2+$ & $1+$ & $1+$ & - & - \\
\hline 7 & $1+$ & $2+$ & $1+$ & $2+$ & $1+$ & $2+$ & $1+$ & $2+$ & $1+$ & $1+$ & - & $1+$ \\
\hline 8 & $2+$ & $2+$ & $2+$ & $2+$ & $2+$ & $2+$ & $2+$ & $2+$ & $1+$ & $1+$ & - & - \\
\hline
\end{tabular}

- $<3 \%$ of cells positive; $1+, 3-50 \%$ of cells positive; $2+,>50 \%$ of cells positive.

$\mathrm{HGF}$, hepatocyte growth factor; PDGF, platelet derived growth factor; TGF, transforming growth factor.

Table 5 Staining in neurofibroma (NF) and malignant peripheral nerve sheath tumour (MPNST) areas

\begin{tabular}{|c|c|c|c|c|c|c|c|c|}
\hline \multirow[b]{2}{*}{ Case } & \multicolumn{2}{|l|}{$p 53$} & \multicolumn{2}{|c|}{$b c l-2$} & \multicolumn{2}{|c|}{$N-C A M$} & \multicolumn{2}{|c|}{$C D 34$} \\
\hline & $N F$ & $M P N S T$ & $N F$ & $M P N S T$ & $N F$ & $M P N S T$ & $N F$ & $M P N S T$ \\
\hline 1 & - & $1+$ & - & - & - & - & $2+$ & - \\
\hline 2 & - & $1+$ & - & - & - & - & - & - \\
\hline 3 & - & - & $1+$ & $1+$ & - & - & $1+$ & $1+$ \\
\hline 4 & - & - & $1+$ & $1+$ & - & - & $2+$ & $2+$ \\
\hline 5 & - & $1+$ & $1+$ & $1+$ & - & $2+$ & $2+$ & - \\
\hline 6 & - & $1+$ & $1+$ & $1+$ & $2+$ & $2+$ & $1+$ & - \\
\hline 7 & - & - & $1+$ & $1+$ & $1+$ & $2+$ & - & - \\
\hline 8 & - & $1+$ & $1+$ & $1+$ & $1+$ & $2+$ & $1+$ & $1+$ \\
\hline
\end{tabular}

- $<3 \%$ of cells positive; $1,3-50 \%$ of cells positive; $2, \geqslant 50 \%$ of cells positive.

$\mathrm{N}-\mathrm{CAM}$, neural cell adhesion molecule. 


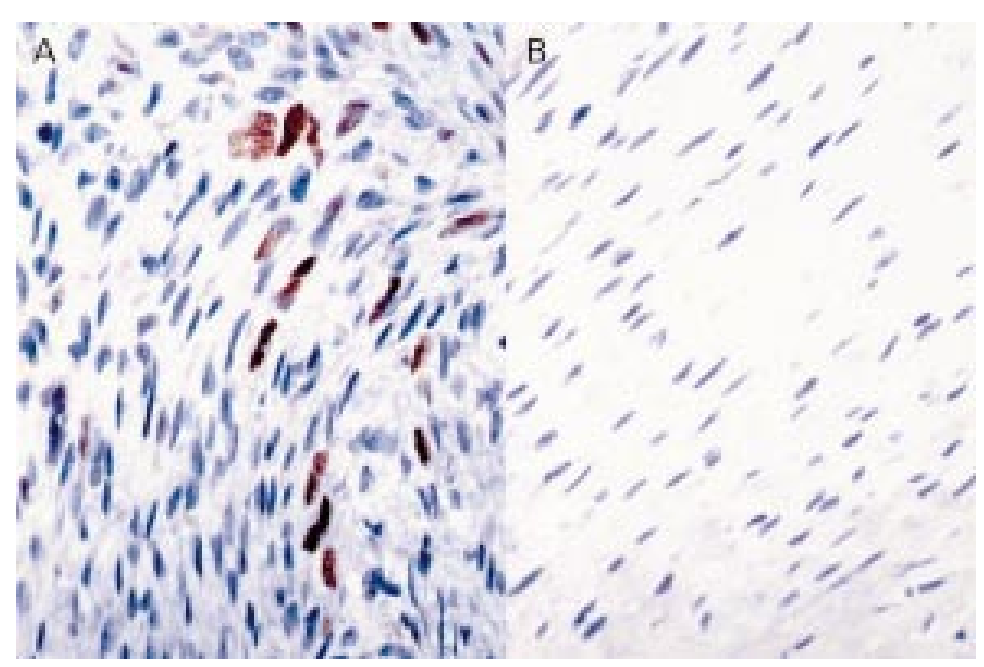

Figure 6 Immunohistochemical staining patterns for p53. Staining in the neurofibroma $(B)$ is negative, whereas that in the MPNST $(A)$ is graded as $1+$ (case 8) (original magnification, $\times 400$ ). when comparing benign and malignant neurogenic tumours.

Moreover, it has also been shown that the anti-apoptotic protein bcl-2 is expressed to some extent in gliomas, and is expressed more often in low grade astrocytomas than in malignant gliomas. ${ }^{36}$ We found that bcl-2 was expressed in both the MPNST and neurofibroma areas, and that there was no definite distinction between the two regarding bcl-2 immunoreactivity. Consequently, it seems that bcl-2 does not play an important role in the progression of MPNST.

In contrast, in our study, five of the eight MPNSTs arising within a neurofibroma showed immunoreactivity for p53 in the sarcomatous areas, but not in the adjacent neurofibromatous areas. Furthermore, there was no occurrence of p53 immunoreactivity in either the sarcomatous or neurofibromatous areas in three of the eight cases. Our data differ from the report of Halling et al because they reported that all seven MPNSTs arising within a neurofibroma showed immunoreactivity for p53 in the sarcomatous areas. ${ }^{6}$ Differences in the anti-p53 antibody used may underlie the differences seen in these results. However, our study showed that $\mathrm{p} 53$ plays an important role in the evolution of MPNST from neurofibroma. Our data were compatible with molecular data, which showed that $17 \mathrm{p}$ deletion or mutations of p53 occurred during the malignant transformation from neurofibroma to MPNST. $^{31}$

In our study, N-CAM immunoreactivity in the MPNST areas was higher than that in the neurofibroma areas in three of the eight cases. Our results are similar to those of Miettinen et al, who reported that consistent N-CAM immunoreactivity was seen in malignant schwannoma, whereas only variable staining was seen in benign schwannoma. ${ }^{32}$ The reason for this has yet to be determined. CD34 is a myeloid progenitor cell antigen, which is also present in dermal dendritic cells, endothelial cells, and some subsets of fibroblasts. ${ }^{33}{ }^{34}$ In our series, the immunoreactivity of neurofibroma was higher than that of MPNST in three of the eight cases. Some fibroblasts in neurofibroma seem to express CD34, but this expression seems to be lost during the process of MPNST formation. There is also the possibility that $\mathrm{N}$-CAM and CD34 play a role in the malignant transformation of neurogenic tumours.

In conclusion, our immunohistochemical study showed that TGF- $\beta 1 / \mathrm{TGF}-\beta$ receptor type II, HGF- $\alpha / \mathrm{c}-\mathrm{met}$, and $\mathrm{p} 53$ seem to play a role in the malignant transformation of neurofibroma to MPNST. In addition, these factors might be useful in distinguishing clinicopathologically between MPNST and neurofibroma. However, further studies to determine the precise mechanism behind this transformation are necessary.

The surgical specimens and clinical data were obtained from the following institutes: Kyushu University, National Kyushu suyama Red Cross Hospital. The authors sincerely thank the above institutes for contributing these materials, in addition to above institutes for contributing these materials, in addition to
Dr Y Hachitanda Y (Kitakyushu Medical Center), and Dr S Dr Y Hachitanda Y (Kitakyushu Medical Center), and Dr S
Kawauchi (Kyushu Cancer Center) for their technical advice 
and thoughtful comments. This study was supported in part by a grant in aid for cancer research from the Fukuoka Cancer Society, Fukuoka, and a grant in aid for general scientific from the Ministry of Education, Science and Culture (09470052, 12670167), Tokyo, Japan.

1 Ducatman BS, Scheithauer BW, Piepgras DG, et al. Malignant peripheral nerve sheath tumors. A clinicopathologic study of 120 cases. Cancer 1986;57:2006-21.

2 Deimling AV, Krone W, Menon AG. Neurofibromatosis type 1: pathology, clinical features and molecular genetics. Brain Pathol 1995;5:153-62.

3 Miracco C, Montesco MC, Santopietro R, et al. Proliferative activity, angiogenesis, and necrosis in peripheral nerve sheath tumors: a quantitative evaluation for prognosis. Mod Pathol 1996;9:1108-17.

4 DeClue JE, Papageorge AG, Fletcher JA, et al. Abnormal regulation of mammalian $\mathrm{p} 21$ ras contributes to malignan bromatosis. Cell 1992;69:265-73.

5 McCarron KF, Goldblum JR. Plexiform neurofibroma with and without associated malignant peripheral nerve sheath tumor: a clinicopathologic and immunohistochemical tumor: a clinicopathologic and immunohistoch

6 Halling KC, Scheithauer BW, Halling AC, et al. p53 expression in neurofibroma and malignant peripheral nerve sion in neurofibroma and malignant peripheral nerve sheath tumor. An immunohistochemical study of sporadic and NF1 $282-8$.

7 Kindblom LG, Ahlden M, Meis-Kindblom JM, et al. Immunohistochemical and molecular analysis of $\mathrm{p} 53$ MDM2, proliferating cell nuclear antigen and Ki67 in benign and malignant peripheral nerve sheath tumours. Virchows Arch 1995;427:19-26.

8 Legius E, Marchuk DA, Collins FS, et al. Somatic deletion of the neurofibromatosis type 1 gene in a neurofibrosarcoma supports a tumour suppressor gene hypothesis. Nat Genet 1993;3:122-6.

9 Lothe RA, Saeter G, Danielsen HE, et al. Genetic alterations in a malignant schwannoma from a patient with neurofibromatosis (NF1). Pathol Res Pract 1993;189:465-71.

10 Lothe RA, Slettan A, Saeter G, et al. Alterations at chromosome 17 loci in peripheral nerve sheath tumors. F some 17 loci in peripheral nerve
Neuropathol Exp Neurol 1995;54:65-73.

11 Menon AG, Anderson KM, Riccardi VM, et al. Chromosome $17 \mathrm{p}$ deletions and p53 gene mutations associated with the formation of malignant neurofibrosarcomas in von Recklinghausen neurofibromatosis. Proc Natl Acad Sci U S A 1990;87:5435-9.

12 Daimaru Y, Hashimoto H, Enjoji M. Malignant peripheral nerve sheath tumors (malignant schwannomas). An immunohistochemical study of 29 cases. Am $\mathcal{F}$ Surg Pathol 1985;9:434-44

13 Serra E. Puig S. Otero D, et al. Confirmation of a double-hit model for the NF1 gene in benign neurofibromas. $A m^{f}$ Hum Genet 1997;61:512-19.

14 Sheela S, Riccardi VM, Ratner N, et al. Angiogenic and invasive properties of neurofibroma Schwann cells. $f$ Cell Biol 1990;111:645-53

15 Skuse GR, Kosciolek BA, Rowley PT. Molecular genetic analysis of tumors in von Recklinghausen neurofibromatosis: loss of heterozygosity for chromosome 17. Genes Chromosomes Cancer 1989;1:36-41.

16 Skuse GR, Kosciolek BA, Rowley PT. The neurofibroma in von Recklinghausen neurofibromatosis has a unicellular origin. Am f Hum Genet 1991;49:600-7.

17 Wick MR, Swanson PE, Scheithauer BW, et al. Malignan peripheral nerve sheath tumor. An immunohistochemical study of 62 cases. Am f Clin Pathol 1987;87:425-33.

18 Davis JB, Stroobant P. Platelet-derived growth factors and fibroblast growth factors are mitogens for rat Schwann cells. F Cell Biol 1990;110:1353-60.
19 Eccleston PA, Funa K, Heldin CH. Expression of platelet-derived growth factor (PDGF) and PDGF alphaand beta-receptors in the peripheral nervous system: an analysis of sciatic nerve and dorsal root ganglia. Dev Biol 1993;155:459-70.

20 Ridley AJ, Davis JB, Stroobant P, et al. Transforming growth factors-beta 1 and beta 2 are mitogens for rat Schwann cells. F Cell Biol 1989;109:3419-24.

21 Schubert D. Synergistic interactions between transforming growth factor beta and fibroblast growth factor regulate Schwann cell mitosis. F Neurobiol 1992;23:143-8.

22 Krasnoselsky A, Massay MJ, DeFrances MC, et al. Hepatocyte growth factor is a mitogen for Schwann cells and is present in neurofibromas. F Neurosci 1994;14:7284-90.

23 Ratner N, Lieberman MA, Riccardi VM, et al. Mitogen accumulation in von Recklinghausen neurofibromatosis. Ann Neurol 1990;27:298-303.

24 Wrana JL, Atissano L, Carcano J, et al. TGF $\beta$ signals through a heteromeric protein kinase receptor complex. Cell 1992;71:1003-14.

25 Taipale J, Saharinen J, Keski-Oja J. Extracellular matrixassociated transforming growth factor-beta: role in cancer cell growth and invasion. Adv Cancer Res 1998;75:87-134.

26 Rao UN, Sonmez-Alpan E, Michalopoulos GK. Hepatocyte growth factor and c-MET in benign and malignant peripheral nerve sheath tumors. Hum Pathol 1997;28:1066-70.

27 Ebert M, Yokoyama M, Friess $H$, et al. Coexpression of the c-met proto-oncogene and hepatocyte growth factor in pancreatic cancer. Cancer Res 1994;54:5775-8.

28 Naka T, Iwamoto Y, Shinohara N, et al. Expression of c-met proto-oncogene product (c-MET) in benign and malignant bone tumors. Mod Pathol 1997;10:832-8.

29 Legius E, Dierick H, Wu R, et al. TP53 mutations are frequent in malignant NF1 tumors. Genes Chromosomes Cancer 1994;10:250-5.

30 Schneider-Stock R, Oda Y, Roessner A, et al. New splicing mutation in exon 5-6 of the p53-tumor suppressor gene in a malignant schwannoma. Hum Mutat 1997;9:91-4.

31 Menon AG, Anderson KM, Riccardi VM, et al. Chromosome $17 \mathrm{p}$ deletions and p53 gene mutations associated with the formation of malignant neurofibrosarcomas in von Recklinghausen neurofibromatosis. Proc Natl Acad Sci U S A 1990;87:5435-9.

32 Miettinen M, Cupo W. Neural cell adhesion molecule distribution in soft tissue tumors. Hum Pathol 1993;24:62-

33 Miettinen M, Lindenmayer AE, Chaubal A. Endothelial cell markers $\mathrm{CD} 31, \mathrm{CD} 34$, and $\mathrm{BNH} 9$ antibody to $\mathrm{H}$-and Y-antigens - evaluation of their specificity and sensitivity in he diagnosis of vascular tumors and comparison with von Willebrand factor. Mod Pathol 1994;7:82-90.

34 Nickoloff BJ. The human progenitor cell antigen (CD34) is localized on endothelial cells, dermal dendritic cells, and perifollicular cells in formalin-fixed normal skin, and on proliferating endothelial cells and stromal spindle-shaped cells in Kaposi's sarcoma. Arch Dermatol 1991;127:523-9.

35 Gerdes J, Li L, Schluter C. Immunochemical and molecular biologic characterization of the cell proliferation associated nuclear antigen that is defined by the monoclonal antibody Ki-67. Am f Pathol 1991;138:867-73.

36 Krajewski S, Krajewska M, Ehrmann J, et al. Immunohistochemical analysis of Bcl-2, Bcl-X, Mcl-1, and Bax in tumors of central and peripheral nervous system origin. $\mathrm{Am}$ 7 Pathol 1997;150:805-14.

37 Nakasu S, Nakasu Y, Nioka H, et al. Bcl-2 protein expression in tumors of the central nervous system. Acta Neuropathol 1994;88:520-6. 